\title{
Detection of novel Chlamydiae and Legionellales from human nasal samples of healthy volunteers
}

\author{
Daniele Corsaro • Danielle Venditti
}

Received: 9 May 2014 / Accepted: 5 February 2015 /Published online: 20 February 2015

(C) Institute of Microbiology, Academy of Sciences of the Czech Republic, v.v.i. 2015

\begin{abstract}
Chlamydiae are intracellular bacterial parasites of eukaryotes, ranging from amoebae to humans. They comprise many novel members and are investigated as emerging pathogens. Environmental studies highlighted similarities between the ecologies of chlamydiae and legionellae, both groups being important agents of respiratory infections. Herein, we analyzed nasal samples from healthy persons, searching for the presence of amoebae, chlamydiae and legionellae. From a total of 25 samples, we recovered by PCR eight samples positive to chlamydiae and six samples positive to legionellae. Among these samples, four were positive to both organisms. The sequencing of $16 \mathrm{~S}$ rDNAs allowed to identify (i) among Chlamydiae: Parachlamydia acanthamoebae, Chlamydophila psittaci, Chlamydophila felis, and members of Rhabdochlamydiaceae, Simkaniaceae and E6 lineage and (ii) among Legionellaceae: Legionella longbeachae, Legionella bozemanii and Legionella impletisoli. Unexpectedly, we also recovered Diplorickettsia sp. Amoebae collected from nasal mucosae, Acanthamoeba and Vermamoeba, were endosymbiont-free, and chlamydiae revealed refractory to amoeba coculture. This study shows common exposure to chlamydiae and legionellae and suggests open air activities like gardening as a probable additional source of infection.
\end{abstract}

D. Corsaro $(\bowtie) \cdot$ D. Venditti

CHLAREAS Chlamydia Research Association, 12 rue du

Maconnais, 54500 Vandoeuvre-lès-Nancy, France

e-mail: corsaro@voila.fr

D. Corsaro

Laboratory of Soil Biology, Institute of Biology, University of

Neuchatel, Neuchatel, Switzerland

D. Venditti

TREDI Research Department, Faculty of Medecine, Technopôle de Nancy-Brabois, 9, Avenue de la Forêt de Haye, B.P. 184, 54505 Vandœuvre-lès-Nancy, France

\section{Introduction}

Chlamydiae are intracellular bacteria living inside eukaryotic hosts. The well-known Chlamydiaceae infect vertebrates, and various species are responsible for acute or chronic respiratory infections in humans, mainly causing atypical pneumonia. Chlamydia trachomatis, a major sexually transmitted human pathogen, may cause respiratory pathologies in newborns and infants through perinatal transmission (Darville 2005; Hammerschlag 2004). Respiratory infection by Chlamydophila spp. is through direct transmission. Chlamydophila pneumoniae, widespread in several vertebrates (Bodetti et al. 2002), is endemic in human populations and responsible for about $10 \%$ of community-acquired pneumonia (Burillo and Bouza 2010; Hammerschlag 2004). Less common agents are of zoonotic origin, primarily the avian chlamydiae causing psittacosis, i.e. Chlamydophila psittaci and new Chlamydophila spp. (Beeckman and Vanrompay 2009; Sachse et al. 2014). Chlamydophila felis causes ocular and respiratory diseases in cats, but its role is likely underestimated, due to difficulties to differentiate among very closely related species, and because this species does not seem to be restricted to cats (Corsaro and Venditti 2004; Trávniček et al. 2002; Pantchev et al. 2010).

Additional novel chlamydial lineages/families were discovered, some of which apparently associated to respiratory illness in humans and therefore investigated as emerging pathogens (Corsaro and Venditti 2004; Corsaro and Greub 2006; Corsaro et al. 2003). Simkania negevensis (Simkaniaceae), discovered as a cell culture contaminant in Israel, occurs prevalently in children and shows a worldwide distribution (e.g. Heiskanen-Kosma et al. 2008; Nascimento-Carvalho et al. 2009). The bovine abortion agent Waddlia chondrophila (Waddliaceae) and members of the Rhabdochlamydiaceae have been also recovered in respiratory samples (Haider et al. 2008). Simkania and Waddlia are able to grow in 
amoebae, and both species have been associated with water, as well as several Rhabdochlamydiaceae which may also be recovered through amoeba coculture, with the notable exception of Rhabdochlamydia spp. (Codony et al. 2012; Corsaro et al. 2009; Kahane et al. 2007; Michel et al. 2004, 2005; Pérez et al. 2012).

However, the most important novel chlamydiae possibly behaving like emerging pathogens are members of the family Parachlamydiaceae, naturally inhabiting free-living naked amoebae. The first member, Parachlamydia acanthamoebae, was discovered as endosymbionts (strains Bn9 and Berg17) of Acanthamoeba spp. isolated from the nasal mucosa of healthy persons in Germany (Amann et al. 1997; Michel et al. 1994). A first evidence for a possible pathogenic role of this organism came from its recovery (Hall's coccus) within an Acanthamoeba isolated from the source of an outbreak of humidifier fever in the USA (Lewis et al. 1990; Birtles et al. 1997). Successive studies reported additional recovery of parachlamydiae species in respiratory samples (Casson et al. 2008; Corsaro et al. 2001, 2002a; Haider et al. 2008). By comparing sequences obtained from bovine abortion samples and their cattle drinking water, Wheelhouse et al. (2011) find identical chlamydial sequences, further indicating the potential pathogenic role of these microorganisms and the water as a main biotope.

What emerges from the various studies is an unexpected diversity of chlamydial lineages possibly implicated in human as well as in animal diseases, and a likely key role of amoebae as vectors, possibly via the respiratory route. Some novel chlamydiae recall in various aspects the ecology of Legionella species and their association to respiratory infections (Borella et al. 2005; Fields et al. 2002; Muder and Yu 2002).

Herein, we analyzed nasal samples from healthy persons for the presence of amoebae, chlamydiae, and legionellae.

\section{Materials and methods}

Nasal samples $(n=25)$ were collected from adult healthy volunteers, none of which working with the searched microorganisms, by using sterile cotton swabs soaked in sterile distilled water (2-ml final volume). For each sample, aliquots of $500 \mu \mathrm{l}$ were used in parallel to inoculate $1.5 \%$ non-nutrient agar (NNA) plates seeded with Escherichia coli to recover amoebae and to extract whole DNA for chlamydiae and legionellae 16S rDNA PCR (see below).

NNA plates inoculated with nasal samples were incubated at room temperature for 3 weeks and observed daily for the emergence of amoebae. Recovered amoebae were identified by amplification and sequencing of a portion of the $18 \mathrm{~S}$ rDNA by using eukaryotic primers $6 \mathrm{~F}$ (5'-CCA GCT CYA AKA
GCG TAT ATT-3) and 9R (5'-GTT GAG TCR AAT TAA GCC GC-3'), under reaction conditions of $5 \mathrm{~min}$ at at $94{ }^{\circ} \mathrm{C}$, followed by 35 cycles at $94{ }^{\circ} \mathrm{C}$ for $1 \mathrm{~min}$, $55^{\circ} \mathrm{C}$ for $30 \mathrm{~s}, 72{ }^{\circ} \mathrm{C}$ for $1 \mathrm{~min}$, with a final elongation at $72{ }^{\circ} \mathrm{C}$ for $10 \mathrm{~min}$ (Corsaro et al. 2013a). Recovered amoebae were screened for the presence of chlamydiae or legionellae by specific PCR.

DNA extracted from nasal samples was submitted to PCR with primers specific for the $16 \mathrm{~S}$ rDNA of chlamydiae or legionellae. For chlamydiae, almost full 16S rDNA was amplified by using pan-chlamydia primers CF1 (5'-CGT GGA TGA GGC ATG CRA GTC G-3'), CR6 (50-GTC ATC RGC CYYACC TTV SRC RYY TCT-3') and CR7 (5'-TAC CTT GTT ACG ACT TMA YCC YAG-3'), under reaction conditions of $5 \mathrm{~min}$ at $94{ }^{\circ} \mathrm{C}$, followed by 35 cycles at $94{ }^{\circ} \mathrm{C}$ for $1 \mathrm{~min}, 60$ or $62{ }^{\circ} \mathrm{C}$ for $30 \mathrm{~s}, 72{ }^{\circ} \mathrm{C}$ for $1 \mathrm{~min}$ and $30 \mathrm{~s}$, with a final extension at $72{ }^{\circ} \mathrm{C}$ for $10 \mathrm{~min}$ (Corsaro et al. 2002b). All samples were tested also as semi-nested PCR, starting with the products obtained with CF1/CR7 diluted 1:100, and using CR6 as inner primer. For legionellae, a 660-bp portion of the gene was amplified by using the primers Leg225 (5'-AAG ATT AGC CTG CGT CCG AT- $\left.3^{\prime}\right)$ and Leg858 (5'-GTC AAC TTA TCG CGT TTG CT-3') (Miyamoto et al. 1997), under reaction conditions of $5 \mathrm{~min}$ at $94{ }^{\circ} \mathrm{C}$, followed by 35 cycles at $94{ }^{\circ} \mathrm{C}$ for $1 \mathrm{~min}, 54{ }^{\circ} \mathrm{C}$ for $30 \mathrm{~s}, 72{ }^{\circ} \mathrm{C}$ for $1 \mathrm{~min}$, with a final extension at $72^{\circ} \mathrm{C}$ for $10 \mathrm{~min}$, as modified from Corsaro et al. (2010b).

A subset of nasal samples tested positive to chlamydia PCR was successively used for Acanthamoeba coculture, as described previously (Corsaro et al. 2009, 2010a). Briefly, $100 \mu \mathrm{l}$ of samples was inoculated and 10-fold-diluted onto 6-well microplates containing Acanthamoeba in Page's Amoeba Saline (PAS). Microplates were centrifuged, thus incubated at room temperature or at $32{ }^{\circ} \mathrm{C}$ in a humidified atmosphere in the dark. Successive amoeba cocultures (coculture II) were performed 5 days later, starting from $100 \mu \mathrm{l}$ of coculture I wells. DNA was extracted from wells I and II and retested by PCR.

All DNA extractions were performed with the Wizard Genomic DNA kit (Promega) according to the manufacturer's recommendations.

Purified PCR products were sequenced with the same primer sets and a series of inner primers by using the BigDye Terminator Cycle kit. Sequences were edited by using BioEdit and analyzed through BLAST server to search for closest relatives. SSU rDNA sequences retrieved from GenBank were aligned by using Muscle.

Phylogenetic analyses were performed by applying maximum likelihood (ML, GTR, G+I:4 model) with TREE FINDER (Jobb et al. 2004), and distance (neighbor-joining, NJ) and maximum parsimony (MP) with MEGA5 (Tamura et al. 2011), with 1000 bootstraps. Similarity values were calculated with BioEdit. 


\section{Results}

Amoeba recovery

Three nasal samples inoculated onto NNA resulted positive for amoebae. The strains were identified by $18 \mathrm{~S}$ rDNA sequencing as Acanthamoeba sp. genotype T4 (two samples) and Vermamoeba vermiformis. All amoeba strains resulted negative to specific chlamydia and legionella PCR.

Pan-chlamydia PCR and phylogenetic analysis

Eight nasal samples resulted positive to pan-chlamydia PCR, but no amoeba was recovered onto NNA plates from them. Direct sequencing of PCR products allowed unambiguous identification of seven chlamydial species belonging to five families: Parachlamydiaceae, E6 lineage, Rhabdochlamydiaceae, Simkaniaceae and Chlamydiaceae.

Sequences from two samples (NS2 and NS7) revealed to be identical each other and belonging to Parachlamydia acanthamoebae (99.7 \% with strain Bn9).

Sequences from samples NS11 and NS13 formed two distinct phylotypes within the E6 lineage, having as closest relatives (95-96\% sequence similarity) uncultured clone EP912A0005 from Hawaiian lava tube (Northup et al. 2011), and mud pond strain cvE18 (Corsaro and Venditti 2009), respectively.

The sequence from sample NS3 emerges as a new phylotype within the Rhabdochlamydiaceae, showing only 90.4$91.8 \%$ similarity with Rhabdochlamydia spp. recovered directly from arthropods (Corsaro et al. 2007; Kostanjsek et al. 2004) or from environmental samples, strains cvE88 (Corsaro and Venditti, unpubl.) and KF-9 (GenBank acc. no. EF445478, Shivaji and Pradhan, unpubl.). The closest relative to NS3, with $93.7 \%$ sequence similarity, is the clone CN554 from human respiratory sample (Haider et al. 2008).

The sequence from sample NS16 belongs to the E9 subclade within the Simkaniaceae (Corsaro and Venditti 2009; Corsaro et al. 2002b), sharing $97.6 \%$ similarity with cvE9.

The two sequences from samples NS7 and NS9 revealed to be Chlamydophila psittaci and Chlamydophila felis, respectively, showing $99.9 \%$ similarity with respective closest strains Cps-NJ1 and Cfe-Cello.

Phylogenetic analysis performed on almost full 16S rDNA confirmed the relationships among the various novel chlamydial phylotypes and their closest relatives with high bootstrap values (Fig. 1). For Chlamydiaceae, a 1150-bp phylogenetic tree was built (Fig. 2) to include also partial sequences of four and three strains of $C$. psittaci (strains cvCps1 to cvCps4) and C. felis (strains cvCfe1 to cvCfe3), respectively, detected from respiratory samples in our previous study (Corsaro et al. 2002a). The $C$. felis sequences emerged as independent from one another, while the $C$. psittaci sequences clustered into two groups including strains associated to human infections, Frt6Hu/Cal10 and HU/Borg, respectively (Fig. 2).

Legionella PCR and phylogenetic analysis

Nine samples resulted positive to legionella PCR, but unambiguous sequences were obtained only for six PCR products. Samples were all negative for amoeba recovery onto NNA; however, four samples, NS3, 11, 13 and 16, resulted positive also for chlamydiae (see above).

Sequences obtained from samples 11, 13,16 and 23 can be assigned to three known Legionella species: legNS11 and legNS13 were $100 \%$ identical with $L$. longbeachae sg-1 and $L$. bozemanii sg-1, respectively. The sequence legNS16 shared $99.8 \%$ similarity with the fountain strain CD-1 (Guan et al. 2012), and $99.3-99.6 \%$ with the various strains of L. longbeachae, and it could thus be assigned to that species. Similarly, legNS23 could be assigned to L. impletisoli (Kuroki et al. 2007), sharing $99.5 \%$ similarity, while the second closest relative was L. yabuuchiae, with only $98.7 \%$. The legNS3 appeared to be a new species, having as closest relative (99\%) the undetermined Legionella sp. strain legS088 recovered from a water treatment plant (Corsaro et al. 2010b).

Unexpectedly, sequence of sample NS15 shared $98.7 \%$ similarity with the novel ixodid symbiont Diplorickettsia massiliensis (Mediannikov et al. 2010), and about $96 \%$ with uncultured clones from lakes.

Phylogenetic tree based on the 640-bp portion confirmed the relationships of the recovered legionellae sequences with high to moderate bootstraps, as well as the emergence of our putative Diplorickettsia sp. along Diplorickettsia massiliensis within the Coxiellaceae (Fig. 3).

Acanthamoeba coculture

Because of the peculiar nature of some novel chlamydiae recovered by PCR, nasal samples nos. 3, 11, 13 and 16 were submitted to Acanthamoeba coculture, starting from two $100-\mu \mathrm{l}$ aliquots and incubating the microplates at different temperatures. Only some wells of the plates incubated at room temperature tested PCR-positive, but coculture II resulted always negative. These chlamydial strains were thus considered non-cultivable in Acanthamoeba.

\section{Discussion}

In our study, we found human nasal samples from healthy volunteers, positive for Parachlamydia acanthamoebae and new members of E6 lineage, Simkaniaceae (E9 subclade) and Rhabdochlamydiaceae, as well as C. psittaci and C. felis. In addition, we also detected four Legionella species, and 


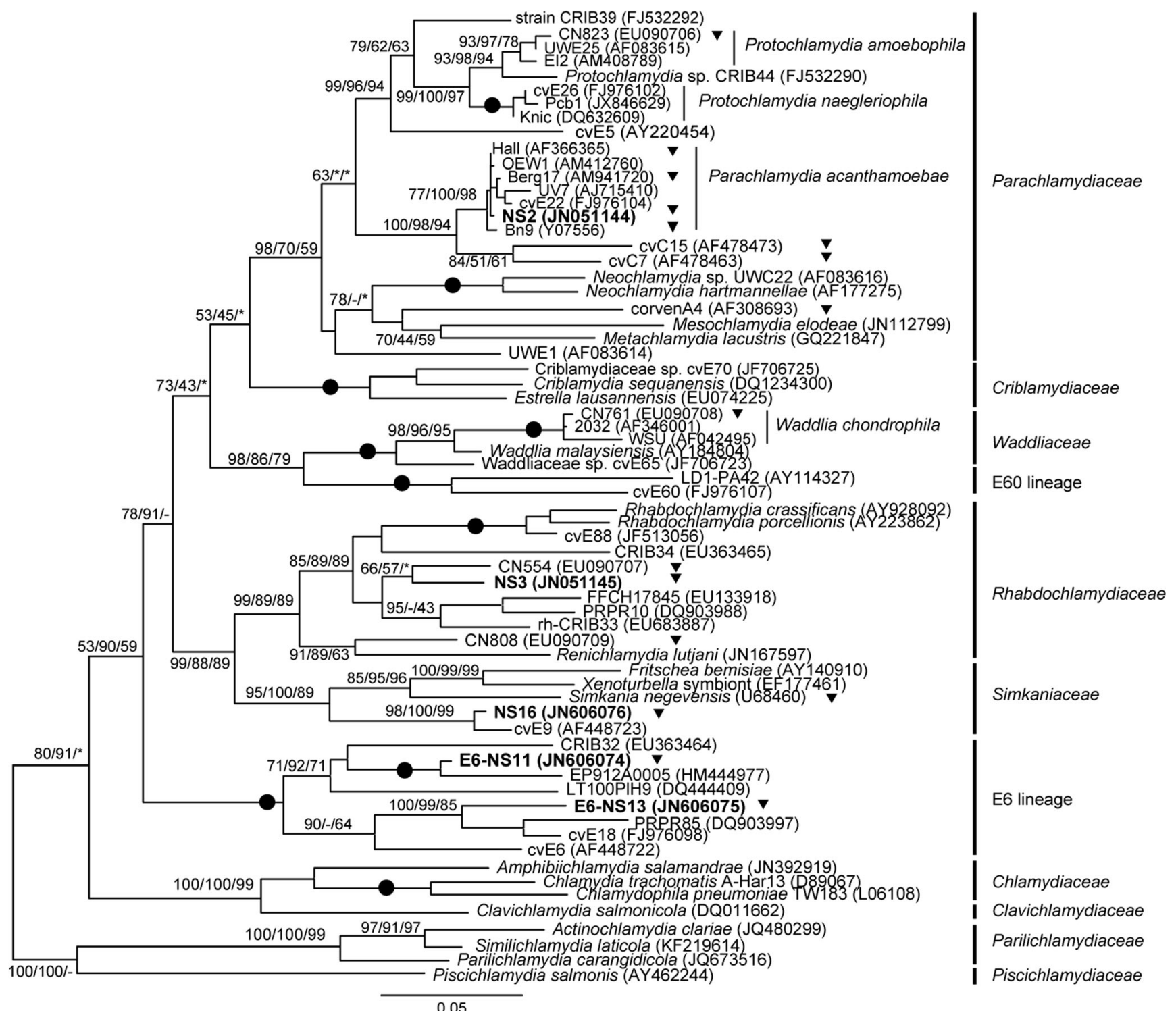

Fig. 1 Maximum likelihood phylogenetic tree of the Chlamydiae. Strains recovered in this study are shown in bold. Association to human disease or recovery from human clinical samples is marked by a triangle. Numbers at the nodes represent bootstrap values obtained by ML/NJ/MP;

unexpectedly the tick endosymbont Diplorickettsia sp. Four samples were positive for both chlamydiae and legionellae.

Amoebae isolated from nasal samples revealed free of endosymbionts, and our attempts to isolate the novel chlamydiae in Acanthamoeba coculture were all unsuccessful. This culture approach permits the recovery of various novel chlamydiae (Corsaro and Greub 2006; Corsaro et al. 2009). However, its efficiency depends on the amoeba species or strain used as host (Corsaro et al. 2010a; 2013a, 2013a, b; Michel et al. 2004), and it is limited by the refractoriness of several chlamydial lineages to grow in amoebae (Corsaro and Venditti 2009), including those symbionts of arthropods like Fritschea (Everett et al. 2005) and Rhabdochlamydia filled circles represent bootstrap values of $100 \%$ obtained with all three methods; asterisk, value $<40 \%$; hyphen, node not supported. Tree rooted on Piscichlamydiaceae + Parilichlamydiaceae

(Corsaro, unpubl.), and those infecting fish (Corsaro and Karlsen, unpubl.).

The chlamydiae recovered herein showed high biodiversity (7 species out 8 strains) and frequency (9 out 25 samples, $36 \%$ ). This was also observed for the legionellae, with four species recovered in five samples $(20 \%)$. Four samples were positive for both microorganisms (16\%). The limited number and/or type of examined samples may likely have biased these results. Previous studies conducted on larger numbers of clinical respiratory samples recovered about $3-11 \%$ chlamydiapositive samples by using PCR approaches. Haider et al. (2008) analyzed community-acquired pneumonia patients for the presence of chlamydiae, by using specific PCR 


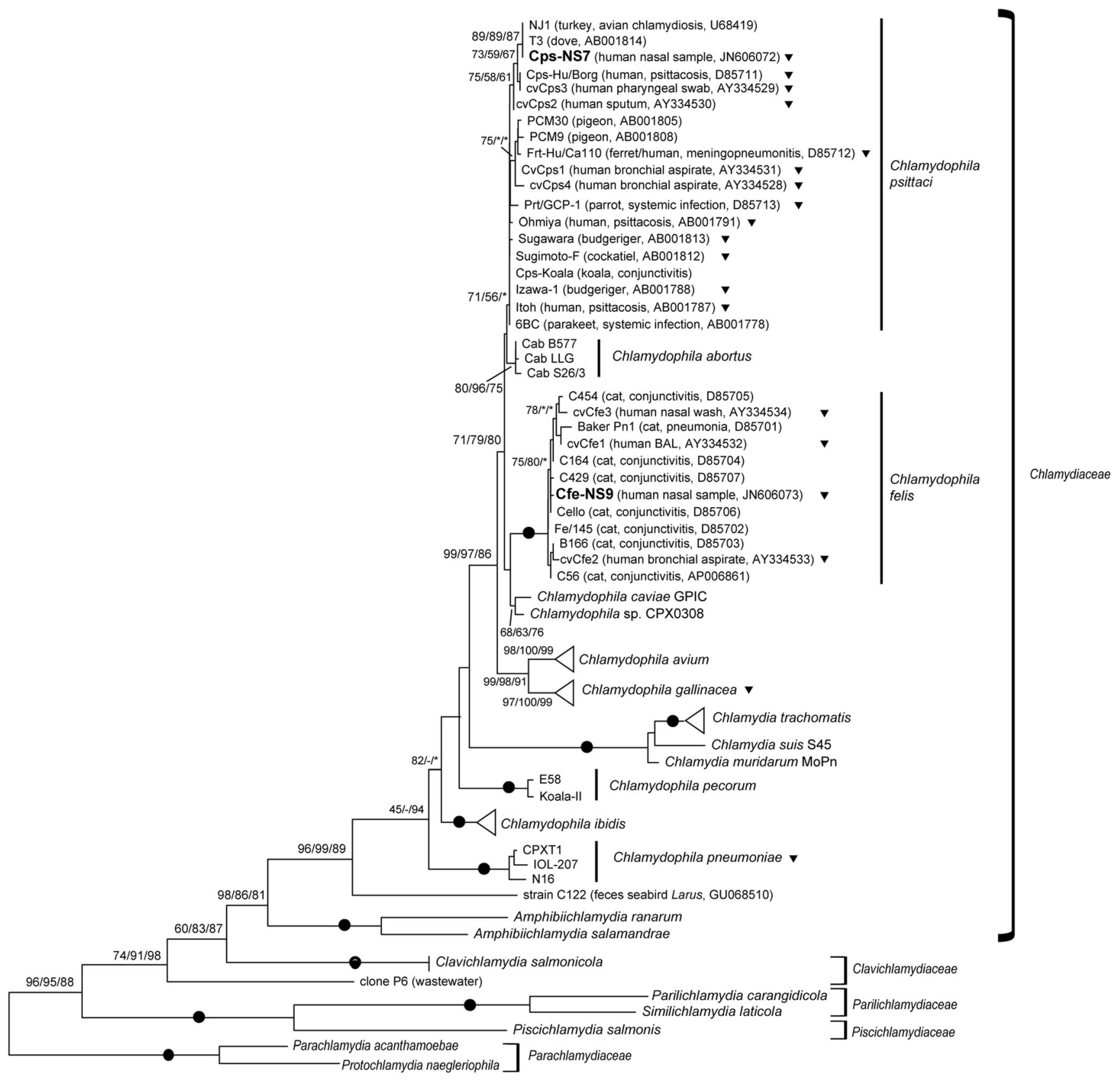

\subsection{6}

Fig. 2 Partial ML (1150-bp) phylogenetic tree of the Chlamydiaceae and closest relatives. Main family and genus names are indicated; Parachlamydiaceae used as outgroup. Strains recovered in this study are shown in bold. Association to human diseases or recovery from

targeting nearly full $16 \mathrm{~S}$ rDNA, and found 14 out 387 samples positive (3.6\%). They identified five species, dominated by Parachlamydia acanthamoebae $(n=7)$ and Protochlamydia amoebophila $(n=4)$. The remaining species were Waddlia chondrophila and two novel putative genus-level lineages, CN554 and CN808, within the Rhabdochlamydiaceae.

In a previous study focusing on differential diagnosis of chlamydial and mycoplasma respiratory infections with human clinical samples is marked by a triangle. Numbers at the nodes represent bootstrap values obtained by ML/NJ/MP; filled circles represent bootstrap values of $100 \%$ obtained with all three methods; asterisk, value $<40 \%$; hyphen, node not supported

specific PCR, we found 18 out 190 samples positive for chlamydiae $(9.4 \%)$, and we identified six chlamydial taxa: Chlamydophila pneumoniae $(n=8)$, Chlamydophila psittaci $(n=4)$, Chlamydophila felis ( $n=3)$ (Fig. 2), and three distinct genus-level lineages within Parachlamydiaceae (Corsaro et al. 2001, 2002a). By contrast, Greub et al. (2004) recovered 7 out 444 Acanthamoeba coculture positive (1.6\%) from nasal swabs of patients $(5 / 100)$, homeless $(1 / 244)$ and healthy 


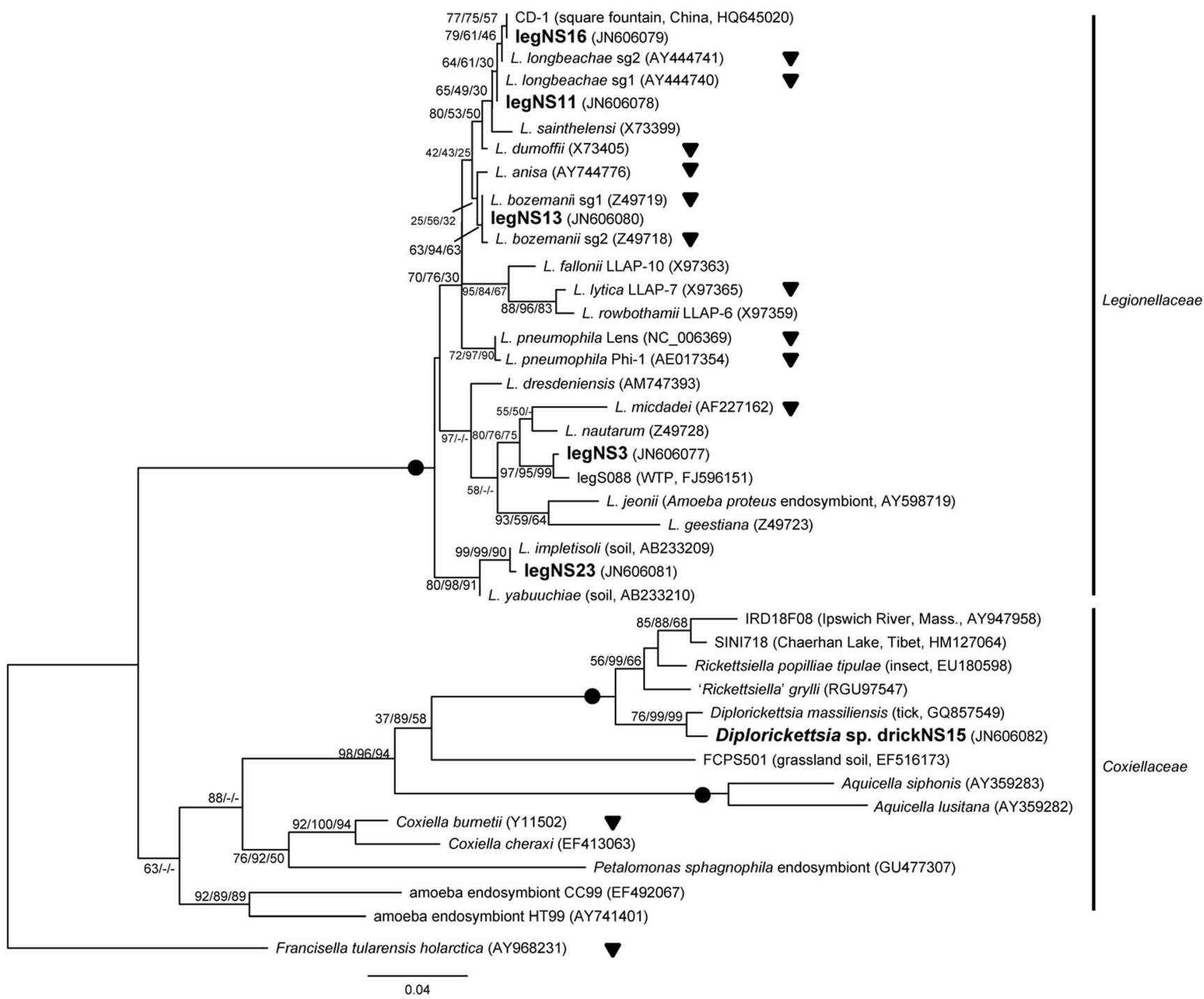

Fig. 3 Partial ML (650-bp) phylogenetic tree of the Legionellales. Strains recovered in this study are shown in bold. Association to human diseases is marked by a triangle. Numbers at the nodes represent

(1/100) persons. However, they used eubacterial PCR and identified both alpha-Proteobacteria and beta-Proteobacteria as well as Flavobacteria, but they found neither chlamydiae nor legionellae.

By using a set of taxon-specific real-time PCRs, Niemi et al. (2011) reported the recovery of only Rhabdochlamydia spp. in 16 out 136 samples (11.7\%), while specific real-time PCR for other four novel chlamydiae resulted negative. However, the authors have neither identified the Rhabdochlamydia species, despite the technique employed could potentially allow to recover at least four distinct taxa, nor they screened their samples for the presence of other recognized pathogenic chlamydia species.

More recently, Lienard et al. (2011) applied a real-time PCR targeting all chlamydiae to 422 nasopharyngeal swabs from children with $(n=265)$ and without $(n=157)$ pneumonia, finding 48 bootstrap values obtained by ML/NJ/MP; filled circles represent bootstrap values of $100 \%$ obtained with all three methods; hyphen node not supported. Tree rooted on Francisella tularensis

positive samples $(11.4 \%)$. The authors reported an important diversity of phylotypes, by assigning 200-bp sequenced PCR products to various chlamydial families. However, in order to identify such taxa, they wrongly applied to such small fragments, similarity percentage cut-offs proposed for almost full gene sequences. This gives rise to incorrect identification of various sequences, as revealed by the accurate analysis of their data. As an example, some of such partial sequences were assigned to the Criblamydiaceae, because having 92-93\% identity values with either Criblamydia or Estrella (see Table 5, Lienard et al. 2011). However, one sequence (HE20008, Genbank acc. no. HQ721215) is actually closest (97-98\%) to various uncultured clones ( $>1300 \mathrm{bp}$ ) belonging to the Rhabdochlamydiaceae (e.g. clones GP27807eO9 and FFCH17845, GenBank acc. nos. JN616113 and EU133918). Another sequence (GE10047, Genbank acc. no. HQ721195) shares the same identity value 
with members from at least two other families, namely Mesochlamydia (Parachlamydiaceae) and Amphibiichlamydia (Chlamydiaceae), thus resulting 'unclassifiable'. Finally, the clone 530-2, used to identify another sequence (GE10027, GenBank acc. no. HQ721193), was wrongly assigned to Criblamydiaceae, while it is notoriously known as a member of the 'Amazon group' of Protochlamydia within the Parachlamydiaceae (Corsaro and Venditti 2006). The use of small fragment sequences to infer phylogenetic or taxonomic information is clearly inappropriate and misleading, adding only confusion in groups like Chlamydiae widely composed of apparently new phylotypes.

Legionellae are thought to be amoeba parasites able to cause pneumonia in humans by resisting to the macrophages. However, their interaction in the environment may be more complex, involving a wide range of chemical and physical factors, as well as biofilms and various prokaryotic and eukaryotic microbes (Taylor et al. 2009). In addition, both in-field and experimental studies indicate that freshwater and soil invertebrates may play a role in the maintenance and diffusion of these bacteria (Brassinga et al. 2010; Castellani Pastoris et al. 1989). Such a more complex ecology is supported by the recent highlightings on the soil- and compost-associated legionellae (Casati et al. 2009; O'Connor et al. 2007; Pravinkumar et al. 2010) and is also reflected by genomic data (Cazalet et al. 2010).

Recent studies characterizing nasal and oropharyngeal microbiotas showed them to be highly complex and variable over time, depending mainly on both individual and seasonal factors, but also on other environmental variables (Bogaert et al. 2011; Camarinha-Silva et al. 2012; Lemon et al. 2010). Meteorological factors like wind and rain (Jones and Harrison 2004) and garden activities (Casati et al. 2009; O'Connor et al. 2007; Pravinkumar et al. 2010) increase exposure to inhalation of bioaerosols originating from soil. Four out of six of our volonteers positive for chlamydiae and/or legionellae have regular garden activities, and another works with plant tissues infected by fungi.

The legionellae recovered in the present study, L. longbeachae, L. bozemanii and L. impletisoli, all inhabit soils and have been associated to infections by garden activities (Casati et al. 2009). The new ixodid endosymbiont Diplorickettsia (Mediannikov et al. 2010) would be eventually expected in blood as a consequence of tick bite. Its recovery in one of our samples was likely due to crashed infected ticks contaminating in some way the nose. However because of the increasing discovery of new endosymbionts in unexpected niches (e.g. Kim et al. 2010), the possibility of a Diplorickettsia sp. inhabiting a soil or freshwater protist cannot be excluded. Chlamydiae have been recovered from almost all types of environments and are at present largely constituted by a huge number of phylotypes with unknown hosts. It might be surprising that one of our recovered phylotypes, NS11, has as closest relative a clone obtained from Hawaiian lava tubes. However, advances in geomicrobiology showed that unexplored microbiota, including various bacteria as well as microbial eukaryotes, is present in both carbonate (karst) and non-carbonate (pseudokarst) caves (Engel 2010, 2011).

Human beings appear commonly exposed to various species of Parachlamydiaceae (Casson et al. 2008; Corsaro et al. 2001, 2002a; Haider et al. 2008). Parachlamydia acanthamoebae, herein found twice, is the most frequent and important, while the other ones are likely occasional cases from environmental exposure (Amann et al. 1997; Birtles et al. 1997; Corsaro et al. 2013b). Also, the role of Chlamydophila spp. as rare but important respiratory agents of zoonotic origin is known, and we recovered $C$. psittaci and C. felis in this study and in a previous one (Corsaro et al. 2002a). Birds and cats are frequent inhabitants or visitors of gardens; thus, they may release C. psittaci and C. felis, respectively, in soil and on plant surfaces. Indeed, it is known that C. psittaci may pass through bird faeces, while cats usually mark the territory by spraying urine and rubbing plants with the head with facial gland secretions, an activity possibly favouring C. felis dissemination. This would imply that both species are able to survive in the environment. Many studies confirmed Simkania negevensis to be a respiratory pathogen. We did not recover this species, but a member of the E9 subclade of Simkaniaceae, previously found only in freshwater ponds (Corsaro and Venditti 2009; Corsaro et al. 2002b). As for the members of the E6 lineage recovered in this study, the most probable source for these chlamydiae appears to be garden activity, since the same samples resulted positive to L. longbeachae and L. bozemanii. Finally, the closest relative of our rhabdochlamydial strain was previously found in a respiratory sample (Haider et al. 2008). Various molecular-based studies reported the presence of chlamydial sequences associated with plants (Bragina et al. 2012; Bulgari et al. 2012; Filion et al. 2004; Kim et al. 2003; Sagaram et al. 2009; Trivedi et al. 2010; Zhang et al. 2011). These partial sequences (400-700 bp) share high similarity values, up to $98 \%$, with known members of at least four families, i.e. Parachlamydiaceae, Rhabdochlamydiaceae, Simkaniaceae and lineage E6. Although not predominant, representing generally about $2-10 \%$ of clone libraries, these sequences indicate that various chlamydial families may be part of the rhizosphere microbiota, but also may be found as epiphytic and perhaps as endophytic microorganisms. Most of these chlamydiae are likely harboured by protistans and (micro)invertebrates inhabiting the rhizosphere and the phyllosphere, and amoebae infected by chlamydiae have been isolated from leaves (Corsaro et al. 2013a). In addition, their endophytic nature may be explained in some cases by the transmission of chlamydiae from the original host. For example, some clones, wrongly identified as "uncultured Simkania" (Sagaram et al. 2009; Trivedi et al. 2010), are indeed closest to Fritschea spp., which are endosymbionts of whiteflies and scale insects, plant phloem feeder hemipterans.

In clinical diagnosis, searching for responsible pathogen(s) by PCR methods targeting specific nucleic acids in clinical 
samples is useful as a confirmatory strategy, and to increase the diagnostic yield. In the case of some fastidious microorganisms, like chlamydiae and legionellae, molecular-based diagnosis is often preferred. Coupled protocols were also developed to target together well-recognized species like Chlamydophila pneumoniae, Legionella pneumophila or Mycoplasma pneumoniae, on different types of clinical samples (e.g. Corsaro et al. 1999; Diederen et al. 2009; Cho et al. 2012). The implementation of broad-range PCR primers in both clinical and environmental surveys showed that many more taxa may be detected, especially for the groups treated herein. In several cases, however, it could not be clearly established if the amplified DNA was from living or dead organisms. In the case of clinical samples, the recovery of DNA of novel but poorly known organisms does not mean necessarily that they are true new pathogens; they may indeed also be commensals or simply contaminants. Even if not completely, this problem may be solved by applying, e.g. ethidium (EMA) or propidium (PMA) monoazide dyes, which leave available for the PCR the DNA of living cells, by selectively binding to the DNA of dead cells (Fittipaldi et al. 2012). In any case, efforts to isolate living microorganisms should be performed, since false-positive results from the applications of the various molecular methods are always possible. This is especially important when novel taxa are involved, requiring further efforts to develop new isolation methods, search for potential natural hosts, as well as reliable molecular-based identifications.

In conclusion, we showed common exposure to chlamydiae and legionellae in healthy adults. Available data on identified species and recreational/work activities of some participants to the study suggest that the soil and plant matter, e.g. garden activity, may be an additional possible source of transmission.

\section{References}

Amann R, Springer N, Schönhuber W, Ludwig W, Schmid EN, Müller KD, Michel R (1997) Obligate intracellular bacterial parasites of acanthamoebae related to Chlamydia spp. Appl Environ Microbiol 63:115-121

Beeckman DS, Vanrompay DC (2009) Zoonotic Chlamydophila psittaci infections from a clinical perspective. Clin Microbiol Infect 15:1117

Birtles RJ, Rowbotham TJ, Storey C, Marrie TJ, Raoult D (1997) Chlamydia-like obligate parasite of free-living amoebae. Lancet 349:925-926

Bodetti TJ, Jacobson E, Wan C, Hafner L, Pospischil A, Rose K, Timms P (2002) Molecular evidence to support the expansion of the host range of Chlamydophila pneumoniae to include reptiles as well as humans, horses, koalas and amphibians. Syst Appl Microbiol 25:146-152

Bogaert D, Keijser B, Huse S, Rossen J, Veenhoven R, van Gils E, Bruin J, Montijn R, Bonten M, Sanders E (2011) Variability and diversity of nasopharyngeal microbiota in children: A metagenomic analysis. PLOS ONE 6:e1703

Borella P, Guerrieri E, Marchesi I, Bondi M, Messi P (2005) Water ecology of Legionella and protozoan: environmental and public health perspectives. Biotechnol Annu Rev 11:355-380

Bragina A, Berg C, Cardinale M, Shcherbakov A, Chebotar V, Berg G (2012) Sphagnum mosses harbour highly specific bacterial diversity during their whole lifecycle. ISME J 6:802-813

Brassinga AKC, Kinchen JM, Cupp ME, Day SR, Hoffman PS, Sifri CD (2010) Caenorhabditis is a metazoan host for Legionella. Cell Microbiol 12:343-361

Bulgari D, Bozkurt AI, Casati P, Cağlayan K, Quaglino F, Bianco PA (2012) Endophytic bacterial community living in roots of healthy and 'Candidatus Phytoplasma mali'-infected apple (Malus domestica, Borkh.) trees. Antonie Van Leeuwenhoek 102:677-687

Burillo A, Bouza E (2010) Chlamydophila pneumoniae. Infect Dis Clin N Am 24:61-71

Camarinha-Silva A, Jáuregui R, Pieper DH, Wos-Oxley ML (2012) The temporal dynamics of bacterial communities across human anterior nares. Environ Microbiol Rep 4:126-132

Casati S, Giorgia-Martinoni A, Gaia V (2009) Commercial potting soils as an alternative infection source of Legionella pneumophila and other Legionella species in Switzerland. Clin Microbiol Infect 15: 571-575

Casson N, Michel R, Müller KD, Aubert JD, Greub G (2008) Protochlamydia naegleriophila as etiologic agent of pneumonia. Emerg Infect Dis 14:168-172

Castellani Pastoris M, Passi C, Maroli M (1989) Evidence of Legionella pneumophila in some arthropods and related natural aquatic habitats. FEMS Microbiol Lett 62:259-263

Cazalet C, Gomez-Valero L, Rusniok C, Lomma M, Dervins-Ravault D, Newton HJ, Sansom FM, Jarraud S, Zidane N, Ma L, Bouchier C, Etienne J, Hartland EL, Buchrieser C (2010) Analysis of the Legionella longbeachae genome and transcriptome uncovers unique strategies to cause Legionnaires' disease. PLoS Genet 6:e1000851

Cho MC, Kim H, An D, Lee M, Noh SA, Kim MN, Chong YP, Woo JH (2012) Comparison of sputum and nasopharyngeal swab specimens for molecular diagnosis of Mycoplasma pneumoniae, Chlamydophila pneumoniae, and Legionella pneumophila. Ann Lab Med 32:133-138

Codony F, Fittipaldi M, López E, Morató J, Agustí G (2012) Well water as a possible source of Waddlia chondrophila infections. Microbes Environ 27:529-532

Corsaro D, Greub G (2006) Pathogenic potential of novel Chlamydiae and diagnostic approaches to infections due to these obligate intracellular bacteria. Clin Microbiol Rev 19:283-297

Corsaro D, Venditti D (2004) Emerging chlamydial infections. Crit Rev Microbiol 30:75-106

Corsaro D, Venditti D (2006) Diversity of the parachlamydiae in the environment. Crit Rev Microbiol 32:185-199

Corsaro D, Venditti D (2009) Detection of Chlamydiae from freshwater environments by PCR, amoeba coculture and mixed coculture. Res Microbiol 160:547-552

Corsaro D, Valassina M, Venditti D, Venard V, Le Faou A, Valensin PE (1999) Multiplex PCR for rapid and differential diagnosis of Mycoplasma pneumoniae and Chlamydia pneumoniae in respiratory infections. Diagn Microbiol Infect Dis 35:105-108

Corsaro D, Venditti D, Le Faou A, Guglielmetti P, Valassina M (2001) A new chlamydia-like 16S rDNA sequence from a clinical sample. Microbiology 147:515-516

Corsaro D, Venditti D, Valassina M (2002a) New parachlamydial 16S rDNA phylotypes detected in human clinical samples. Res Microbiol 153:563-567

Corsaro D, Venditti D, Valassina M (2002b) New chlamydial lineages from freshwater samples. Microbiology 148:343-344 
Corsaro D, Valassina M, Venditti D (2003) Increasing diversity within Chlamydiae. Crit Rev Microbiol 29:37-78

Corsaro D, Thomas V, Goy G, Venditti D, Radek R, Greub G (2007) 'Candidatus Rhabdochlamydia crassificans', an intracellular bacterial pathogen of the cockroach Blatta orientalis (Insecta: Blattodea). Syst Appl Microbiol 30:221-228

Corsaro D, Feroldi V, Saucedo G, Ribas F, Loret JF, Greub G (2009) Novel Chlamydiales strains isolated from a water treatment plant. Environ Microbiol 11:188-200

Corsaro D, Michel R, Walochnik J, Müller KD, Greub G (2010a) Saccamoeba lacustris, sp. nov. (Amoebozoa: Lobosea: Hartmannellidae), a new lobose amoeba, parasitized by the novel chlamydia 'Candidatus Metachlamydia lacustris' (Chlamydiae: Parachlamydiaceae). Eur J Protistol 46:86-95

Corsaro D, Saucedo Pages G, Catalan V, Loret JF, Greub G (2010b) Biodiversity of amoebae and amoeba-associated bacteria in water treatment plants. Int J Hyg Environ Health 213:158-166

Corsaro D, Müller KD, Wingender J, Michel R (2013a) “Candidatus Mesochlamydia elodeae" (Chlamydiae: Parachlamydiaceae), a novel chlamydia parasite of free-living amoebae. Parasitol Res 112:829-838

Corsaro D, Walochnik J, Venditti D, Müller KD, Michel R (2013b) Molecular identification of a phage-infected Protochlamydia strain naturally harboured by non-encysting Naegleria. Acta Protozool 52: 273-281

Darville T (2005) Chlamydia trachomatis infections in neonates and young children. Semin Pediatr Infect Dis 16:235-244

Diederen BM, Van Der Eerden MM, Vlaspolder F, Boersma WG, Kluytmans JA, Peeters MF (2009) Detection of respiratory viruses and Legionella spp. by real-time polymerase chain reaction in patients with community acquired pneumonia. Scand J Infect Dis 41: $45-50$

Engel AS (2010) Microbial diversity of cave ecosystems. In: Barton L, Mandl M, Loy A (eds), Geomicrobiology: Molecular \& Environmental Perspectives. Springer. pp 219-238

Engel AS (2011) Karst ecosystems. In: Reitner J, Thiel V (eds) Encyclopedia of Geobiology. Springer Encyclopedia of Earth Sciences Series (EESS, formerly Kluwer Edition), Berlin, pp 521553

Everett KDE, Thao M, Horn M, Dyszynski GE, Baumann P (2005) Novel chlamydiae in whiteflies and scale insects: endosymbionts 'Candidatus Fritschea bemisiae' strain Falk and 'Candidatus Fritschea eriococci' strain Elm. Int J Syst Evol Microbiol 55: $1581-1587$

Fields BS, Benson RF, Besser RE (2002) Legionella and Legionnaires' disease: 25 years of investigation. Clin Microbiol Rev 15:506-526

Filion M, Hamelin RC, Bernier L, St-Arnaud M (2004) Molecular profiling of rhizosphere microbial communities associated with healthy and diseased black spruce (Picea mariana) seedlings grown in a nursery. Appl Environ Microbiol 70:3541-3551

Fittipaldi M, Nocker A, Codony F (2012) Progress in understanding preferential detection of live cells using viability dyes in combination with DNA amplification. J Microbiol Methods 91:276-289

Greub G, La Scola B, Raoult D (2004) Amoebae-resisting bacteria isolated from human nasal swabs by amoebal coculture. Emerg Infect Dis 10:470-477

Guan W, Xu Y, Chen DL, Xu JN, Tian Y, Chen JP (2012) Application of multilocus sequence analysis (MLSA) for accurate identification of Legionella spp. isolated from municipal fountains in Chengdu, China, based on 16S rRNA, mip, and rpoB genes. J Microbiol 50: $127-136$

Haider S, Collingro A, Walochnik J, Wagner M, Horn M (2008) Chlamydia-like bacteria in respiratory samples of community acquired pneumonia patients. FEMS Microbiol Lett 281:198-202
Hammerschlag MR (2004) Chlamydia trachomatis and Chlamydia pneumoniae infections in children and adolescents. Pediatr Rev $25: 43-51$

Heiskanen-Kosma T, Paldanius M, Korppi M (2008) Simkania negevensis may be a true cause of community acquired pneumonia in children. Scand J Infect Dis 40:127-130

Jobb G, von Haeseler A, Strimmer K (2004) TREEFINDER: a powerful ghraphical analysis environment for molecular phylogenetics. BMC Evol Biol 4:18

Jones AM, Harrison RM (2004) The effects of meteorological factors on atmospheric bioaerosol concentrations. Sci Total Environ 326:151180

Kahane S, Greenberg D, Newman N, Dvoskin B, Friedman MG (2007) Domestic water supplies as a possible source of infection with Simkania. J Infect 54:75-81

Kim JS, Kwon SW, Jordan F, Ryu JC (2003) Analysis of bacterial community structure in bulk soil, rhizosphere soil and root samples of hot pepper plants using FAME and $16 \mathrm{~S}$ rDNA clone libraries. J Microbiol Biotechnol 13:236-242

Kim E, Park JS, Simpson AG, Matsunaga S, Watanabe M, Murakami A, Sommerfeld K, Onodera NT, Archibald JM (2010) Complex array of endobionts in Petalomonas sphagnophila, a large heterotrophic euglenid protist from Sphagnum-dominated peatlands. ISME J 4: $1108-1120$

Kostanjsek R, Strus J, Drobne D, Avgustin G (2004) 'Candidatus Rhabdochlamydia porcellionis', gen. nov., sp. nov., an intracellular bacterium from hepatopancreas of the terrestrial isopod Porcellio scaber. Int J Syst Evol Microbiol 54:543-549

Kuroki H, Miyamoto H, Fukuda K, Iihara H, Kawamura Y, Ogawa M, Wang Y, Ezaki T, Taniguchi H (2007) Legionella impletisoli sp. nov. and Legionella yabuuchiae sp. nov., isolated from soils contaminated with industrial wastes in Japan. Syst Appl Microbiol 30:273-279

Lemon KP, Klepac-Ceraj V, Schiffer HK, Brodie EL, Lynch SV, Kolter R (2010) Comparative analyses of the bacterial microbiota of the human nostril and oropharynx. MBio 1:e00129-1

Lewis DM, Dutkiewicz J, Sorenson WG, Mamolen M, Hall JE (1990) Microbiological and serological studies of an outbreak of 'humidifier fever' in a print shop. Biodeterior Res 3:467-477

Lienard J, Croxatto A, Aeby S, Jaton K, Posfay-Barbe K, Gervaix A, Greub G (2011) Development of a new chlamydiales-specific realtime PCR and its application to respiratory clinical samples. J Clin Microbiol 49:2637-2642

Mediannikov O, Sekeyová Z, Birg ML, Raoult D (2010) A novel obligate intracellular Gamma-Proteobacterium associated with ixodid ticks, Diplorickettsia massiliensis, gen. nov., sp. nov. PLoS ONE 5: e11478

Michel R, Hauröder-Philippczyk B, Müller KD, Weishaar I (1994) Acanthamoeba from human nasal mucosa infected with an obligate intracellular parasite. Eur J Protistol 30:104-110

Michel R, Steinert M, Zöller L, Hauröder B, Hennig K (2004) Free-living amoebae may serve as hosts for the Chlamydia-like bacterium Waddlia chondrophila isolated from an aborted bovine fotus. Acta Protozool 43:37-42

Michel R, Müller KD, Zöller L, Walochnick J, Hartmann M, Schmid EN (2005) Free-living amoebae serve as host for the Chlamydia-like bacterium Simkania negevensis. Acta Protozool 44:113-121

Miyamoto H, Yamamoto H, Arima K, Fujii J, Maruta K, Izu K, Shiomori T, Yoshida SI (1997) Development of a new seminested PCR method for detection of Legionella species and its application to surveillance of Legionellae in hospital cooling tower water. Appl Environ Microbiol 63:2489-2494

Muder RR, Yu VL (2002) Infection due to Legionella species other than L. pneumophila. Clin Infect Dis 35:990-998

Nascimento-Carvalho CM, Cardoso MRA, Paldianus M, Barral A, Araújo-Neto CA, Saukkoriipi A, Vainionpää R, Leinonen M, Ruuskanen O (2009) Simkania negevensis infection among 
Brazilian children hospitalized with community-acquired pneumonia. J Infect 58:250-253

Niemi S, Greub G, Puolakkainen M (2011) Chlamydia-related bacteria in respiratory samples in Finland. Microbes Infect 13:824-827

Northup DE, Melim LA, Spilde MN, Hathaway JJM, Garcia MG, Moya M, Stone FD, Boston PJ, Dapkevicius MLNE, Riquelme C (2011) Lava cave microbial communities within mats and secondary mineral deposits: Implications for life detection on other planets. Astrobiology 11:601-618

O’Connor BA, Carman J, Eckert K, Tucker G, Givney R, Cameron S (2007) Does using potting mix make you sick? Results from a Legionella longbeachae case-control study in South Australia. Epidemiol Infect 135:34-39

Pantchev A, Sting R, Bauerfeind R, Tyczka J, Sachse K (2010) Detection of all Chlamydophila and Chlamydia spp. of veterinary interest using species-specific real-time PCR assays. Comp Immunol Microbiol Infect Dis 33:473-484

Pérez LM, Codony F, Ríos K, Peñuela G, Adrados B, Fittipaldi M, de Dios G, Morató J (2012) Searching Simkania negevensis in environmental waters. Folia Microbiol 57:11-14

Pravinkumar SJ, Edwards G, Lindsay D, Redmond S, Stirling J, House R, Kerr J, Anderson E, Breen D, Blatchford O, McDonald E, Brown A (2010) A cluster of Legionnaires' disease caused by Legionella longbeachae linked to potting compost in Scotland, 2008-2009. Euro Surveill 15:19496

Sachse K, Laroucau K, Riege K, Wehner S, Dilcher M, Creasy HH, Weidmann M, Myers G, Vorimore F, Vicari N, Magnino S, LieblerTenorio E, Ruettger A, Bavoil PM, Hufert FT, Rosselló-Móra R,
Marz M (2014) Evidence for the existence of two new members of the family Chlamydiaceae and proposal of Chlamydia avium sp. nov. and Chlamydia gallinacea sp. nov. Syst Appl Microbiol 37:79-88

Sagaram US, De Angelis KM, Trivedi P, Andersen GL, Lu SE, Wang N (2009) Bacterial diversity analysis of Huanglongbing pathogeninfected citrus, using PhyloChip arrays and 16S rRNA gene clone library sequencing. Appl Environ Microbiol 75:1566-1574

Tamura K, Peterson D, Peterson N, Stecher G, Nei M, Kumar S (2011) MEGA5: Molecular Evolutionary Genetics Analysis using Maximum Likelihood, Evolutionary Distance, and Maximum Parsimony Methods. Mol Biol Evol 28:2731-2739

Taylor M, Ross K, Bentham R (2009) Legionella, protozoa, and biofilms: interactions within complex microbial systems. Microb Ecol 58: $538-547$

Trávniček M, Mardzinová S, Čisláková L, Valocký I, Weissová T (2002) Chlamydial infection of cats and human health. Folia Microbiol 47: $441-444$

Trivedi P, Duan Y, Wang N (2010) Huanglongbing, a systemic disease, restructures the bacterial community associated with citrus roots. Appl Environ Microbiol 76:3427-3436

Wheelhouse N, Sait M, Gidlow J, Deuchande R, Borel N, Baily J, Caldow G, Longbottom D (2011) Molecular detection of Chlamydia-like organisms in cattle drinking water. Vet Microbiol 152:196-199

Zhang YZ, Wang ET, Li M, Li QQ, Zhang YM, Zhao SJ, Jia XL, Zhang LH, Chen WF, Chen WX (2011) Effects of rhizobial inoculation, cropping systems and growth stages on endophytic bacterial community of soybean roots. Plant Soil 347:147-161 